\title{
An Advanced Clinician Practitioner in Arthritis Care (ACPAC) Maintains a Positive Patient Experience While Increasing Capacity in Rheumatology Community Care
}

\author{
Vandana Ahluwalia' \\ Taucha Inrig $\mathbb{D}^{2}$ \\ Tiffany Larsen ${ }^{3}$ \\ Rachel Shupak ${ }^{4}$ \\ Tripti Papneja' \\ Arthur Karasik ${ }^{5}$ \\ Carol Kennedy ${ }^{2}$ \\ Katie Lundon (iD) \\ 'Division of Rheumatology, Department \\ of Internal Medicine, William Osler \\ Health System, Brampton, ON, Canada; \\ ${ }^{2}$ Musculoskeletal Health and Outcomes \\ Research, St. Michael's Hospital, Toronto, \\ ON, Canada; ${ }^{3}$ Department of \\ Physiotherapy, Headwaters Healthcare \\ Centre, Orangeville, ON, Canada; \\ ${ }^{4}$ Division of Rheumatology, Department \\ of Internal Medicine, St. Michael's \\ Hospital, Toronto, ON, Canada; \\ ${ }^{5}$ Independent Rheumatology Practice, \\ Etobicoke, ON, Canada; ${ }^{6}$ Continuing \\ Professional Development, Faculty of \\ Medicine, University of Toronto, Toronto, \\ ON, Canada
}

Purpose: This study describes patient care experiences of solo-rheumatologist and comanaged care models utilizing an Advanced Clinician Practitioner in Arthritis Care-trained Extended Role Practitioner (ACPAC-ERP) in three community rheumatology practices.

Materials and Methods: Patients with inflammatory arthritis (IA) were assigned to care provided by one of three ( 2 senior, 1 early-career) community-based rheumatologists (usual care), or an ACPAC-ERP (co-managed care) for the 6-months following diagnosis. Patient experiences were surveyed using validated measures of patient satisfaction (Patient Doctor Interaction Scale-PDIS), global ratings of confidence and satisfaction, referral patterns, disease activity (RADAI) and self-perceived disability (HAQ-Disability) as well as demographic information. Practice capacity was evaluated 18-months prior to, and across, the study period.

Results: Of 55 participants (mean age 56.6 years, 61.8\% female), 33 received co-managed care. Most participants were diagnosed with rheumatoid arthritis $(65.5 \%)$ with a median symptom duration of 1.1 years. At 6-months, patients from both models of care were equally satisfied in terms of the information provided (usual care 4.6 vs co-managed care $4.7 / 5=$ greater satisfaction), rapport with health-care provider (4.6 vs $4.6 / 5)$ and having needs met (4.7 vs $4.5 / 5)$. Overall satisfaction was high ( 87.2 vs $85.3 / 100=$ completely satisfied) as was confidence in the system by which care was received ( 85.0 vs $82.1 / 100=$ completely confident). Usual care patients reported higher perceived disability than co-managed patients (HAQ-Disability $0.5 \mathrm{vs} 0.2 / 3=$ unable to do). Significant differences in overall RADAI score $(\mathrm{p}=0.014)$ were found between the two models. The senior rheumatologist, with a previously saturated practice, attained a $37 \%$ capacity increase for new patients utilizing the co-managed care model.

Conclusion: The ACPAC-ERP model was equivalent to the solo-rheumatologist model with regard to patient experience and satisfaction. A co-management model utilizing a highly trained ACPAC-ERP can increase capacity in community rheumatology clinics for patients newly diagnosed with IA while maintaining confidence and satisfaction with their care.

Keywords: health service accessibility, interprofessional practice, rheumatology, patient satisfaction, quality improvement, extended role practitioner, integrated delivery systems, model of care

\section{Plain Language Summary}

This study was conducted to evaluate a novel role for an Advanced Clinician Practitioner in Arthritis Care-trained (ACPAC) Extended Role Practitioner (ERP) in three community rheumatology practices. Patients with inflammatory arthritis were triaged by the 
ACPAC-ERP and then seen by the rheumatologist to establish a diagnosis. Following the confirmation of the diagnosis, comanaged care was provided by the ACPAC-ERP and the rheumatologist for the first six months of care. This study shows that patients were equally highly satisfied with the care delivered and services provided in the novel co-managed model of care and usual rheumatology practice.

\section{Introduction}

Rheumatoid Arthritis (RA) is a chronic, systemic inflammatory disorder that affects many organ systems, but most often attacks synovial joints. The onset of RA can occur at any age and effective treatments now exist. The burden of disease to the patient and the health-care system is greater if patients with inflammatory arthritis are seen later in the evolution of their disease or left untreated. ${ }^{1-5}$

Early diagnosis and treatment with disease-modifying anti-rheumatic drugs (DMARDs) improves patient outcomes and in some cases results in clinical remission. ${ }^{2,3,6}$ In Canada, more than 272,000 people currently live with RA, representing $0.9 \%$ of the Canadian adult population. By 2030, this number is expected to increase to $1.3 \% .^{7-9}$ Increased demand for rheumatology care is a result of multiple factors including an aging population, increasing incidence and prevalence of inflammatory arthritis (IA), and a relative rheumatologist shortage. ${ }^{10}$ There are shared service-demand issues with a known increasing prevalence of patients with inflammatory arthritis in the United States, for example, ${ }^{11}$ that will also be further exacerbated by a concurrent shortage of practicing rheumatology specialists. $^{12}$

In Ontario, Canada, an increasing number of people are living with IA. ${ }^{13,14}$ From 2000 to 2015, the number of rheumatologists increased by $35 \%$, however access to care remained unchanged over this time. ${ }^{15}$ The Canadian Rheumatology Association benchmark of one full-time equivalent (FTE) per 75,000 population is not being met and significant regional variation exists. ${ }^{15}$ Changing demographics of rheumatologists, including aging and retirement, feminization of the specialty, ${ }^{16}$ reduced FTE designation, and clinic saturation are associated with decreased clinical capacity and the current work force shortage. $^{5,14,15}$

Patients with IA conditions are complex and require early intervention to control inflammation, minimize joint damage, and maintain function. Current rheumatology practices are subject to clinic saturation as patients with IA have a chronic disease, are on complex drugs, and require ongoing follow-up by the specialist. As a result, new patients currently constitute only $11 \%$ of the patients seen in Ontario. ${ }^{14}$ Health human resources have not kept pace with growth in the prevalence of RA creating a growth/demand mismatch. The need for improved access to care has been the catalyst for the development of novel allied health practitioner roles ${ }^{17-19}$ that can be locally developed, refined, and delivered throughout the continuum of care. More efficient models of care involving these trained health professionals have been shown to effectively triage patients with IA $^{20-22}$ and increase capacity for new and stable patients.

A new nationally recognized model for arthritis care was developed by the Ontario Rheumatology Association and adapted by the Arthritis Alliance of Canada. ${ }^{8}$ This model of care, where a highly trained extended role practitioner (ERP) co-manages patients with a rheumatologist, has the potential to strengthen the capacity for the rheumatologist to improve rapid access to services for new and flaring IA patients. These ERPs are used at multiple touch points within the model including identification, triage, medical management, education, and patient selfmanagement. ERPs can also support patient and system performance metrics including quality of care measurements.

The Advanced Clinician Practitioner in Arthritis Care (ACPAC) Program ${ }^{23}$ was formally developed in 2005 in recognition of Ontario's need to expand the pool of arthritis care providers. ACPAC program graduates are trained to practice to the full scope of their profession. Under medical directives, they perform delegated activities. Using a co-managed model, these additional activities may include ordering X-rays and blood tests, performing joint injections and advocating for dosage modification of prescription medications. Recent evidence exclusively involving ACPAC-ERPs performing triage of patients with suspected IA in this type of model of care showed significant improvement on access-to-care. ${ }^{21,22}$ This model still requires a rheumatologist's assessment to make a diagnosis and create a treatment plan. Once a treatment plan is established, patients with IA can then be comanaged by the rheumatologist and an appropriately trained and skilled arthritis care provider such as an ACPAC-ERP. This may optimize the rheumatologist's time, thus improving their capacity for patient care.

The purpose of the current study is to describe the patient experience of care provided in both a solorheumatologist and co-managed model of care involving the novel integration of an ACPAC-ERP into three 
community rheumatology practices. This role was based upon an established care pathway to co-manage patients where the rheumatologist paper-triaged (gray-zone) patients who were then physically triaged for suspected IA by the ACPAC-ERP. ${ }^{21}$ As ERPs integrate into healthcare systems and assume novel roles, it is important to capture the yet undescribed patient perspective of the care received from these providers.

\section{Materials and Methods Study Population and Setting}

This study was conducted between October 2015 and September 2017 and included patients from three different community rheumatology practices in the Greater Toronto Area. Each rheumatologist operated at a full-time equivalent (FTE) or greater capacity and had maintained their practices for 33, 23 and 7 years, respectively. An ACPACtrained physiotherapist ERP was employed one day per week per community rheumatology practice site to comanage adult patients newly diagnosed with IA across the first six months of their care. The ACPAC-ERP had worked for 15 years as a physiotherapist and had 9 years of clinical experience co-managing patients within community rheumatology practices.

\section{Inclusion Criteria}

Patients newly diagnosed with IA from the usual care and co-managed care models completed an anonymous crosssectional comparison survey after their 6-month follow-up visit if they were at least 18 years of age and able to complete the survey in English.

\section{Two Models of Care}

Usual Care (solo-rheumatologist): Requires clinical monitoring of patients to assess signs of disease activity, disease progression, and the monitoring of prescription medications (medication adherence, and assessment of drug-related toxicities). Follow-up visits are used to reinforce self-management principles, evaluate comorbid conditions and their treatment, update immunizations, recommend exercises for IA and concomitant noninflammatory musculoskeletal conditions, and make referrals to other health-care professionals when necessary.

Co-Managed Care (ACPAC-ERP and rheumatologist): Co-managed patients are assessed by the ACPAC-ERP for signs of disease activity, monitored for medication adherence/response, assessed for drug-related toxicities, and screened for comorbid conditions. In addition, the ERP provides reinforcement of self-management principles, delivers patient education related to other aspects of life (ie, smoking cessation, exercise, diet, family/social, emotional, and work roles), and makes referrals to other health-care professionals when the expertise required is not within the practitioner's skill set.

\section{Triage Process}

In this study, new referrals were paper triaged into three groups by the rheumatologists:

1. Those patients clearly without IA were paper triaged as routine as per the rheumatologists' usual practices (not included in this study).

2. Patient referrals with strong evidence of IA, based on clinical, laboratory or radiographic findings sent with the referral, were treated as urgent and seen directly by the rheumatologist in a traditional 30-45-minute consultation (usual care).

3. Patients with suspected IA on referral ("grayzone" $)^{21}$ were assigned to the ACPAC-ERP who performed a 45-minute assessment. Following this assessment, the ACPAC-ERP reviewed every case with the rheumatologist to corroborate the history and physical exam. Further investigations were ordered if needed. A provisional diagnosis was made, and a treatment plan was initiated. Where medications were prescribed, the ACPAC-ERP would provide education around potential side effects. At the conclusion of the visit, the ACPACERP dictated the consultation note which was reviewed and signed off by the rheumatologist. The rheumatologist typically would spend 15 minutes, or less, at this co-managed care consultation appointment. Patients in the co-managed care model were followed by both the rheumatologist and ACPAC-ERP at the 3- and 6-month visits. Over a period of 30 minutes, the ACPAC-ERP would initially review the patient's symptoms, medication adherence, side-effects, laboratory and radiographic results, and perform a physical exam to assess joint activity. The ACPAC-ERP reviewed the findings with the rheumatologist and the plan was discussed jointly with the patient. The ACPAC-ERP completed the Electronic Medical Record (EMR) assessment form and faxed notes to the family doctor. In most cases, 
the rheumatologist would spend 5-10 minutes with co-managed care patients during their followup visits.

In both usual care and co-managed models, all prescription medication and dosage changes were made by the rheumatologist. Regardless of the model of care, all patients were managed according to the treat-to-target recommendations ( 3 clinical visits over a 6 -month period). ${ }^{24}$

\section{Recruitment}

Patients were given an introductory letter describing the study and a stamped, pre-addressed envelope containing the survey. Consent was implied if the patient chose to complete the survey and mail it back to the study coordinator.

\section{Survey Content}

The survey content included 2 validated measures of patient satisfaction, disease activity, self-perceived disability, access to care, referrals to other health-care professionals and demographic information. Basic demographic information was collected on each patient including age, gender, diagnosis, disease duration, educational achievement, marital status, living arrangements and global indices of overall health. ${ }^{25}$ Patients were asked to evaluate their disease activity using the Rapid Assessment of Disease Activity Index (RADAI), which combines five items into a single index: current and past global disease activity, pain, morning stiffness and a joint count. ${ }^{26}$ The RADAI score is calculated as the mean of the non-missing items and ranges from $0=$ no disease activity to $10=$ high level of disease activity and is a reliable, valid and responsive measure of disease activity in persons with RA. ${ }^{26}$ A shortened version of the Health Assessment Questionnaire (HAQ 8-item Disability Scale) was used as a self-report measure of disability. The HAQ is a reliable, valid and responsive measure, ${ }^{27}$ with a score calculated as the mean of the 8 -items (ranging from $0=$ no disability to $3=$ greater disability) and has good measurement properties that have been confirmed across many studies and patient populations. ${ }^{28}$

\section{Primary Outcomes (Patient Experience of Care Provided)}

Patient satisfaction was measured by a modified version of the eleven-item Patient Doctor Interaction Scale (PDIS), ${ }^{29}$ validated for patients visiting outpatient settings. ${ }^{30-32}$ One item "I would recommend the Doctor to a friend" was omitted from this tool as patients within this clinical context cannot make recommendations of a Doctor/Advanced Practitioner to a friend and was thus deemed not relevant. In addition, the wording of one item "I feel that I can contact the doctor if I need to" was slightly modified to "I feel that I can contact the doctor's (rheumatologist's) office if I need to" as the advanced practitioner was not in the office daily. Thus, the modified PDIS included 10 items answered on a 5-point Likert scale with anchors of $1=$ strongly disagree and $5=$ strongly agree. Scores were calculated for the three subscales by adding raw scores of items on the subscale and dividing by the number of items, to arrive at a standardized subscale score ranging from 1 to $5 .{ }^{31}$ The adapted version ("Patient-Advanced Practitioner Interaction Scale") reflects the patientadvanced practitioner interaction and has shown good reliability across its subscales: Providing Information $(\alpha=0.89)$, Rapport $(\alpha=0.87)$, and Meeting Patient Needs $(\alpha=0.84){ }^{33}$

An adapted version of the Group Health Association of America's (GHAA) Consumer Satisfaction Survey was used to ask patients to rate their satisfaction with their visit and with their health-care provider and the services that they received. We selected a subset of six items from the GHAA Consumer Satisfaction Survey addressing concepts not captured in other outcome measures. ${ }^{34}$ One additional item was created (teamgenerated item) to ask about the physical examination. Patients were also asked to rate the length of time they waited to be seen in the clinic via a question adapted from Ware's visit specific questionnaire which has been tested for reliability and validity. ${ }^{35}$ The GHAA's Consumer Satisfaction Survey and Ware's question about access to care were adapted so that each item was scored on a scale from $1=$ strongly disagree to $5=$ strongly agree consistent with the PDIS.

Two global questions were asked about patient satisfaction and confidence in the system of care as utilized in a similar evaluative study; ${ }^{36,37}$ both were answered on an 11 -point numerical rating scale $(0=$ not at all satisfied/confident to $100=$ completely satisfied/confident).

Additionally, patients were asked to indicate whether their health-care provider (rheumatologist and/or ACPACERP) provided any education or counseling at their visit regarding their immunization status and if they were provided with referrals to other resources or health-care 
professionals (including physiotherapy, The Arthritis Society, orthotics/splints/footwear, smoking cessation program, heart health program and other educational resources).

\section{Secondary Outcome (Clinic Practice Capacity)}

In addition to evaluating patient experiences between the different models of care, a retrospective analysis was performed on the practice patterns of two (one early career and one senior) of the three community practices represented in our sample. The time frame was 18 months prior to the introduction of an ERP, and the 18 months during which patients were recruited for this study. The number of new patients with IA seen during these two comparable timeframes was extracted from the EMR.

\section{Analysis}

Returned surveys were entered into an Access database. SAS $9.4^{38}$ was used for all analysis. Descriptive statistics were generated to describe the sample and the responses to the outcomes. Shapiro-Wilk Tests of normality were employed: the sample was considered to be normally distributed if the $p$ value was more than 0.05 and non-parametric if the $p$ value was less than 0.05. Unpaired t-tests and Mann-Whitney $U$-Tests were employed to detect for statistical differences in the outcomes between Usual Care and Co-Managed Care Models. A p-value $<0.05$ was considered significant.

\section{Ethical Review}

Permission to perform this study was approved by the Research Ethics Boards (REB) of the William Osler Health System (REB 15-0027, approved 28 September 2015) and St. Michael's Hospital (REB 15-367C, approved 19 February 2016). Individual signed informed consent was not required by these REBs as the return of completed anonymous surveys was considered to imply consent. All patient data were maintained with confidentiality in accordance with the Declaration of Helsinki.

\section{Results}

\section{Participant Description}

A total of 56 participants were recruited for this study. One patient denied having a diagnosis of IA and was excluded from the analysis $(n=55)$. A total of 33 patients from the co-managed care model, and 22 from the usual care model met inclusion criteria and agreed to participate and were included in the analysis. Participants' overall mean age was 56.6 years (range 31-86 years); $61.8 \%$ were female. The majority were diagnosed with RA (65.5\%) with a selfreported median of 1.1 years duration of symptoms. On the global health scale, the majority of participants rated their health at 3 on a scale from 1 to 5 where $5=$ excellent health. Most of the participants were married $(67.3 \%)$ and described their living arrangements as "living with someone" $(81.8 \%)$ in urban settings within central Ontario (85.2\%). No statistically significant differences were noted between the two models of care in terms of age, gender and a diagnosis of RA. Other diagnoses (eg, AS, PMR, SLE, PsA) yielded sample sizes too small to report without risking the identification of patients in an anonymous survey. Additionally, no significant differences were observed in the number of months since the onset of symptoms of inflammatory arthritis, months since diagnosis, confidence participants had in the model of care they experienced, and satisfaction with system of care. Statistically significant differences are found between the two models of care in the overall RADAI score $(p=0.014)$, joint tenderness $(p=0.015)$ and joint count $(p=0.011)$ (Table 1).

\section{Primary Outcomes}

Participants from both the usual care and co-managed models were highly satisfied with the care they received as measured by the Patient-Healthcare Provider Interaction subscales. Participants from both models reported similar scores on the Providing Information subscale items (mean $4.6 / 5$ vs $4.7 / 5=$ strongly agree), the Patient Needs subscale (4.7/5 vs $4.5 / 5=$ strongly agree) and the Modified Rapport subscale (mean $4.6 / 5$ vs $4.6 / 5=$ strongly agree). The adapted GHAA Consumer Satisfaction Survey results demonstrated that participants from both the usual and comanaged models of care were highly satisfied with the care they received in terms of obtaining their medical history (mean 4.6 vs $4.7 / 5=$ strongly agree), explaining investigations (mean 4.7 vs $4.6 / 5=$ strongly agree), having the opportunity for discussion (mean 4.5 vs $4.6 / 5=$ strongly agree) and their questions answered (mean 4.6 vs $4.6 / 5=$ strongly agree). Participants were also highly satisfied with recommendations received (mean 4.4 vs 4.5 / $5=$ strongly agree) and educational materials provided (mean 4.3 vs $4.2 / 5=$ strongly agree). In terms of global confidence and satisfaction with the system of care, no statistically significant difference was found between participants from both models of care (Table 2). 
Table I Participant Descriptors in Usual Care versus Co-Managed Care Models

\begin{tabular}{|c|c|c|c|}
\hline Variable & Whole Sample $\mathbf{n}=55$ & Usual Care $n=22$ & Co-Managed Care $n=33$ \\
\hline \multicolumn{4}{|l|}{ Age (Years) } \\
\hline Mean (SD) & 56.6 years $(15.1)$ & 59.5 years $(14.5)$ & 54.6 years $(15.1)$ \\
\hline Median (IQR) & $57.0(46.0-68.0)$ & $65.5(52.0-68.0)$ & $55.0(42.0-65.0)$ \\
\hline \multicolumn{4}{|l|}{ Gender } \\
\hline \multicolumn{4}{|l|}{ n (\%) } \\
\hline Female & $34(61.8 \%)$ & $13(59.1 \%)$ & $21(63.6 \%)$ \\
\hline \multirow{2}{*}{\multicolumn{4}{|c|}{$\begin{array}{l}\text { Diagnosis (some patients indicated having more than one } \\
\text { diagnoses) }\end{array}$}} \\
\hline & & & \\
\hline \multicolumn{4}{|c|}{ n (\%) } \\
\hline RA & $36(65.5 \%)$ & $14(63.4 \%)$ & $22(66.7 \%)$ \\
\hline PSA & $8(14.6 \%)$ & $*$ & $*$ \\
\hline AS & $5(9.1 \%)$ & $*$ & * \\
\hline PMR & $5(9.1 \%)$ & $*$ & * \\
\hline \multicolumn{4}{|c|}{ Duration of Symptoms (Months) } \\
\hline Mean (SD) & $45.0(71.9)$ & $61.5(91.8)$ & $32.1(49.7)$ \\
\hline Median (IQR) & $14.0(9.0-42.0)$ & $19.0(12.0-48.0)$ & $12.0(8.0-24.0)$ \\
\hline \multicolumn{4}{|l|}{ Months since Diagnosis } \\
\hline Mean (SD) & $36.7(76.1)$ & $41.4(84.7)$ & $33.6(71.3)$ \\
\hline Median (IQR) & $8.0(6.0-16.0)$ & $12.0(6.0-14.0)$ & $7.0(6.0-18.0)$ \\
\hline \multicolumn{4}{|c|}{ Overall Health ( $I=$ poor, $5=$ excellent) } \\
\hline Median (Range) & $3(I-5)$ & $3(2-5)$ & $3(I-5)$ \\
\hline \multicolumn{4}{|l|}{ Education Achieved } \\
\hline \multicolumn{4}{|l|}{ n (\%) } \\
\hline High School or Less & $14(35.5 \%)$ & $7(31.8 \%)$ & $7(21.2 \%)$ \\
\hline College/University degree & $40(72.7 \%)$ & $14(63.6 \%)$ & $26(78.8 \%)$ \\
\hline \multicolumn{4}{|l|}{ Working Status } \\
\hline \multicolumn{4}{|l|}{ n (\%) } \\
\hline Full-time or Self Employed & $29(52.7 \%)$ & $8(36.4 \%)$ & $21(63.6 \%)$ \\
\hline Retired & $14(25.5 \%)$ & $6(27.2 \%)$ & $8(24.2 \%)$ \\
\hline \multicolumn{4}{|l|}{ Marital Status } \\
\hline \multicolumn{4}{|l|}{ n (\%) } \\
\hline Married & $37(67.3 \%)$ & $15(68.2 \%)$ & $22(66.7 \%)$ \\
\hline \multicolumn{4}{|l|}{ Living Arrangements } \\
\hline \multicolumn{4}{|l|}{ n (\%) } \\
\hline With someone else & $45(81.8 \%)$ & $17(77.3 \%)$ & $28(84.9 \%)$ \\
\hline \multicolumn{4}{|l|}{ Geography } \\
\hline \multicolumn{4}{|l|}{ n (\%) } \\
\hline Metropolitan Toronto & $13.0 \%$ & $9.1 \%$ & $16.0 \%$ \\
\hline Urban, Central Ontario & $85.2 \%$ & $90.9 \%$ & $81.3 \%$ \\
\hline \multicolumn{4}{|c|}{$\begin{array}{l}\text { Disease Activity: RADAI Item Arthritis Activity past } 6 \\
\text { months ( } 0=\text { none, } 10=\text { very severe) }\end{array}$} \\
\hline Median (Range) & $5(1-10)$ & $5(2-10)$ & $5(1-10)$ \\
\hline
\end{tabular}

(Continued) 
Table I (Continued).

\begin{tabular}{|c|c|c|c|}
\hline Variable & Whole Sample $n=55$ & Usual Care $n=22$ & Co-Managed Care $n=33$ \\
\hline $\begin{array}{l}\text { Joint Tenderness today** }(0=\text { none, } 10=\text { very severe }) \\
\text { Median (Range) }\end{array}$ & $3(0-9)$ & $4(0-9)$ & $2(0-9)$ \\
\hline $\begin{array}{l}\text { Arthritis Pain today ( } 0=\text { none, } 10=\text { very severe) } \\
\text { Median (Range) }\end{array}$ & $3(0-9)$ & $4(0-8)$ & $2(0-9)$ \\
\hline $\begin{array}{l}\text { Joint Stiffness today } \\
\text { Yes } \mathrm{n}(\%) \\
\text { Median Duration }(1<30 \text { mins to } 6=\text { all day })\end{array}$ & $\begin{array}{l}27(49.1 \%) \\
2\end{array}$ & $\begin{array}{l}13(59.1 \%) \\
3\end{array}$ & $\begin{array}{l}14(42.4 \%) \\
\text { I }\end{array}$ \\
\hline $\begin{array}{l}\text { Total Joint count today** } \\
\text { Mean (SD) }\end{array}$ & $7.0(8.5)$ & $10.1(9.8)$ & $4.9(6.9)$ \\
\hline $\begin{array}{l}\text { RADAI Score** }(0-10=\text { high level of disease activity) } \\
\text { Mean (SD) }\end{array}$ & $3.2(2.0)$ & $4.0(1.9)$ & $2.6(1.9)$ \\
\hline $\begin{array}{l}\text { Impact of Arthritis on Life HAQ disability subscale ( } \\
\text { items/0-3=unable to do) } \\
\text { Mean (SD) }\end{array}$ & $0.3(0.4)$ & $0.5(0.5)$ & $0.2(0.4)$ \\
\hline
\end{tabular}

Notes: *Unable to report $(n<5)$. **Statistically significant difference between the 2 models of care $(p \leq 0.05)$.

\section{Referrals and Education Provided}

During the 6-month follow-up visit, more patients from the usual vs co-managed care models reported discussing education and referral to community resources. Patients from the usual care model reported being referred to physiotherapy $(45.5 \%$ vs $20.0 \%)$ more frequently (Table 3).

\section{Secondary Outcome}

A single community site utilizing similar administrative systems allowed the practice patterns of an early career ( $<7$ years) and a more established senior rheumatologist ( $>23$ years) to be reviewed prior to and during the study period. The established rheumatologist's practice revealed a $37 \%$ increase in capacity to accommodate new patients within the context of the co-managed care model introduced in this 18-month study. Capacity change was not noted in the early career rheumatologist's practice across the same time period (Table 4).

\section{Discussion}

A new care model utilizing an ACPAC-ERP in community rheumatology practice to co-manage patients with suspected IA has been previously established. ${ }^{20-22}$ The integration of ERPs in a triage role has been well received in both community- and hospital-based rheumatology models of care. $^{39}$ The present study further evaluated the perspective of the patient newly diagnosed with IA on care delivered and satisfaction with services provided by an ERP, working with a rheumatologist, across the first 6 months of treatment. The care provided in the co-managed care model was compared to that of usual care within 3 community rheumatology practices. Patient satisfaction with care and their trust in their health-care providers has been shown to influence health-related behaviours, ${ }^{40-42}$ communication of important information, ${ }^{40}$ and treatment outcomes. $^{43-46}$ The results of this study align with those of Warmington et al, where $98 \%$ of the patients felt the arthritis care they received from an ACPAC-ERP working within a co-management model was comparable to what was previously received from other health-care professionals. $^{33}$

The surveys administered at the 6-month follow-up visit asked patients about their care and services received providing a snapshot of their experience at that encounter. In this study, patients at their 6-month follow-up visit were equally satisfied and expressed confidence with care received in both models. Education on pursuing a healthy lifestyle, smoking cessation, and co-morbidity management, in conjunction with good medical treatment, is increasingly recognized as important in the comprehensive care of patients with IA. In this study, patients were asked if additional services including education provided on medications and healthy lifestyles, appraisal of 
Table 2 Outcome Measures in Usual versus Co-Managed Models of Care

\begin{tabular}{|c|c|c|c|}
\hline Variable & $\begin{array}{l}\text { Whole Sample } \\
n=55\end{array}$ & $\begin{array}{l}\text { Usual Care } \\
n=22\end{array}$ & $\begin{array}{l}\text { Co-Managed Care } \\
n=33\end{array}$ \\
\hline \multicolumn{4}{|c|}{$\begin{array}{l}\text { Patient-Health Care Provider Interaction Subscales } \\
\text { (scale range } 1-5=\text { greater satisfaction) }\end{array}$} \\
\hline \multicolumn{4}{|c|}{ Mean (SD) } \\
\hline Provide Information & $4.7(0.5)$ & $4.6(0.5)$ & $4.7(0.5)$ \\
\hline Modified Rapport & $4.6(0.5)$ & $4.6(0.6)$ & $4.6(0.5)$ \\
\hline Meeting Patient Needs & $4.6(0.5)$ & $4.7(0.5)$ & $4.5(0.6)$ \\
\hline \multicolumn{4}{|c|}{ Adapted GHAA ( $1=$ strongly disagree, $5=$ strongly agree) } \\
\hline \multicolumn{4}{|c|}{ Mean (SD) } \\
\hline Medical History & $4.6(0.5)$ & $4.6(0.5)$ & $4.7(0.5)$ \\
\hline Investigations Explained & $4.6(0.5)$ & $4.7(0.5)$ & $4.6(0.6)$ \\
\hline Opportunity for Discussion & $4.6(0.6)$ & $4.5(0.7)$ & $4.6(0.6)$ \\
\hline Answers to Questions & $4.6(0.7)$ & $4.6(0.7)$ & $4.6(0.7)$ \\
\hline Helpful Recommendations & $4.5(0.7)$ & $4.4(0.8)$ & $4.5(0.7)$ \\
\hline Educational Materials & $4.2(0.9)$ & $4.3(0.9)$ & $4.2(0.8)$ \\
\hline \multicolumn{4}{|c|}{$\begin{array}{l}\text { Team-Generated Item ( } I=\text { strongly disagree, } 5=\text { strongly } \\
\text { agree) }\end{array}$} \\
\hline \multicolumn{4}{|c|}{ Mean (SD) } \\
\hline Physical Exam & $4.6(0.6)$ & $4.5(0.7)$ & $4.7(0.5)$ \\
\hline \multicolumn{4}{|c|}{ Adapted Ware Item ( $\mid=$ strongly disagree, $5=$ strongly agree) } \\
\hline \multicolumn{4}{|c|}{ Mean (SD) } \\
\hline Waiting in Clinic & $4.2(0.8)$ & $4.4(0.8)$ & $4.2(0.9)$ \\
\hline \multicolumn{4}{|c|}{ Global Confidence $(0-100=$ completely confident $)$} \\
\hline Mean (SD) & $83.3(17.5)$ & $85.0(13.4)$ & $82.1(19.7)$ \\
\hline Median (IQR) & $90.0(80.0-100.0)$ & $80.0(70.0-100.0)$ & $90.0(80.0-90.0)$ \\
\hline \multicolumn{4}{|c|}{ Global Satisfaction $(0-100=$ completely satisfied $)$} \\
\hline Mean (SD) & $86.1(15.2)$ & $87.2(13.5)$ & $85.3(16.2)$ \\
\hline Median (IQR) & $90.0(80.0-100.0)$ & $90.0(80.0-100.0)$ & $90.0(80.0-100.0)$ \\
\hline
\end{tabular}

immunization status, and if appropriate referrals to other resources/health-care providers were made. Both the usual care and co-managed care models were equally good at providing education on pharmacologic treatment. Early IA management is often focused on prescribing medications to manage pain, control inflammation, and improve function. This is time-consuming and leaves little time to address comorbidities. Rheumatologists have taken the lead on discussion and management of comorbidities as they have recognized the increased morbidity and mortality associated with cardiac diseases, infections and osteoporosis which are prevalent in these patients. However, this is still poorly done in practice as is reflected in the present study. Twice as many referrals were made for physiotherapy/orthotic footwear/splinting in the usual care model. In the co-managed care model, the patient additionally benefited from the professional physiotherapy expertise of the ACPAC-ERP within the clinical visit. The co-managed care model adds value by avoiding duplication of services that are within the team members' expertise, thus reducing health-care costs.

Patients with IA are at increased risk for infection associated with the disease and the use of immunosuppressive medications. ${ }^{47,48}$ A population-based observational study in a large sample of patients with RA from 17 countries showed that influenza and pneumococcal vaccination was performed according to recommendations in only $10 \%$ of patients. ${ }^{49}$ Overall, vaccination discussion, planning and administration was low in the present study. This could be ascribed to the seasonal nature of influenza, and in the present study patients were asked to reflect on vaccination discussions at the 
Table 3 Referrals and Education Provided in Usual versus Co-Managed Models of Care

\begin{tabular}{|c|c|c|c|}
\hline Variable & $\begin{array}{l}\text { Whole Sample } \\
n=55\end{array}$ & $\begin{array}{l}\text { Usual Care } \\
n=22\end{array}$ & $\begin{array}{l}\text { Co-Managed Care } \\
n=33\end{array}$ \\
\hline \multicolumn{4}{|c|}{ Referrals Provided to Allied Health and Community } \\
\hline \multicolumn{4}{|c|}{ Resources } \\
\hline \multicolumn{4}{|l|}{ n (\%) } \\
\hline Physiotherapy & $16(30.1 \%)$ & $10(45.5 \%)$ & $6(20.0 \%)$ \\
\hline \multicolumn{4}{|l|}{ n (\%) } \\
\hline Arthritis Society Referral (TAS and/or eTAS) & $9(16.4 \%)$ & $*$ & $5(15.2 \%)$ \\
\hline \multicolumn{4}{|l|}{ Education Provided } \\
\hline \multicolumn{4}{|l|}{ n (\%) } \\
\hline Medication & $30(57.7 \%)$ & 15 (68.2\%) & $15(50.0 \%)$ \\
\hline Healthy Lifestyle (Exercise, Diet, ADLs) & $22(40.0 \%)$ & $9(27.3 \%)$ & $13(59.1 \%)$ \\
\hline \multicolumn{4}{|l|}{ Vaccination Education } \\
\hline \multicolumn{4}{|l|}{ n (\%) } \\
\hline Flu/Pneumococcal/Hep B/Shingles & $12(21.8 \%)$ & $*$ & $10(30.3 \%)$ \\
\hline \multicolumn{4}{|l|}{ Vaccination Plan } \\
\hline \multicolumn{4}{|l|}{ n (\%) } \\
\hline Flu/Pneumococcal/Hep B/Shingles & $16(29.1 \%)$ & $9(27.3 \%)$ & 7 (2।.2\%) \\
\hline
\end{tabular}

Note: *Unable to report $(n<5)$.

Table 4 Practice Patterns of Community Rheumatologists Prior to and During the Study

\begin{tabular}{|l|l|l|l|l|}
\hline & $\begin{array}{l}18 \text { Months Prior to } \\
\text { Study (Usual Care) }\end{array}$ & $\begin{array}{l}\mathbf{1 8} \text { Months During Study (Usual } \\
+ \text { Co-Managed Care) }\end{array}$ & $\begin{array}{l}\text { Net } \\
\text { Change }\end{array}$ & $\begin{array}{l}\% \\
\text { Change }\end{array}$ \\
\hline $\begin{array}{l}\text { Rheumatologist }>\mathbf{2 3} \text { years in practice } \\
\text { Number of New Patients with IA seen }\end{array}$ & 91 & 125 & +34 & $+37.4 \%$ \\
\hline $\begin{array}{l}\text { Rheumatologist <7 years in practice } \\
\text { Number of New Patients with IA seen }\end{array}$ & 319 & 310 & -9 & $-2.8 \%$ \\
\hline
\end{tabular}

6-month follow-up visit only. The accuracy of patient's recall of their immunization histories could also influence this as their vaccination records from family physicians' offices were not routinely provided. However, given the very low rate of recall in the present study, there is an urgent need to address this care gap.

The Canadian Wait Time Alliance recommends that a patient with RA be seen within 4 weeks of referral, patients with psoriatic arthritis (PsA) seen within 6 weeks of referral and patients with ankylosing spondylitis (AS) within 3 months of referral for optimal care. ${ }^{50}$ In Ontario, Canada, only $59 \%$ of patients with suspected RA are seen within 3 months of referral and only $84 \%$ are seen within 12 months. This indicates wait times are well outside the window of opportunity for quality care. ${ }^{7}$ Most new referrals wait 3-6 months for their first appointment in the community rheumatology practices represented in this sample which is not dissimilar to other Canadian data. $^{51}$

A retrospective analysis showed that in the comanaged care model utilizing an ACPAC-ERP, there was a $37 \%$ increase in the number of new patients seen in the senior rheumatologist's practice during the 18 months of the study, compared to the 18 months prior. This draws attention to the clinic saturation effect experienced in a more established rheumatologist's practice, which results in limited capacity for new consultations. An experienced rheumatologist with a previously saturated clinic attained a significant increase in their capacity to see new patients in the shared care model. With the projected impending retirement of one-third of rheumatologists in the next 5-10 years, ${ }^{10}$ large practices will be inherited by early career 
rheumatologists. A co-management care model may be necessary to accommodate these patients and thus increase capacity for these practices.

Utilizing the co-managed care model, the initial rheumatology consult of a patient with suspected IA was completed by the rheumatologist within 15 minutes. This represents a fraction (one-half to one-third) of the time taken to see a new consult in usual care, thereby increasing the efficiency of the practice. Furthermore, data entry into the EMR, dictation of consultation notes, patient education regarding medications, and discussion of comorbidities, lifestyle and exercise, as well as vaccinations and smoking cessation was completed by the ERP. This allowed the experienced rheumatologist to accommodate an increased number of new patients, thus maximizing efficiency while maintaining a positive patient experience.

\section{Limitations}

A limitation of this study was that all the practices utilized the same highly trained and experienced ACPAC-ERP. Our results may not be generalizable to other settings though our findings are similar to other studies that used a higher number of ERPs with a variation in the length of their work experience. $^{20}$ Additionally, there was a low response rate in the completed surveys, particularly amongst the usual care model. The rheumatologists in the study reported they did not have sufficient administrative support to ensure surveys were routinely handed out. In both models of care, it was noted that many patients spoke English as a second language which limited study eligibility. These clinics are in a geographic location which hosts a large immigrant population. This study relied upon a single survey administered at one point in time (6 months following diagnosis) which may have resulted in patient recall issues. Only two of the practices had sufficient administrative support and EMR knowledge to ensure that the data entered was extractable to assess practice patterns.

\section{Conclusions}

A co-managed care model using a skilled and knowledgeable ACPAC-ERP can increase practice capacity in community rheumatology clinics for patients newly diagnosed with IA while maintaining a positive patient experience. As ERPs integrate into health-care systems and assume novel roles, it is important to continue to capture the patient perspective on the care they receive from these providers and to integrate their voice in decision-making processes. This study showed that the
ERP co-management model was equivalent to the usual care model in terms of patient satisfaction with, and experience of, care provided within the first 6 months following a diagnosis of IA. The co-managed care model was found to increase capacity, particularly in established practices, yet could still bring value to practices of early career rheumatologists.

\section{Abbreviations}

ACPAC, Advanced Clinician Practitioner in Arthritis Care; AS, Ankylosing Spondylitis; DMARDs, Disease Modifying Anti-Rheumatic Drugs; EMR, Electronic Medical Record; ERP, Extended Role Practitioner; GHAA, Group Health Association of America's Consumer Satisfaction Survey; HAQ, Health Assessment Questionnaire; IA, Inflammatory Arthritis; PDIS, Patient Doctor Interaction Scale; PMR, Polymyalgia rheumatica; PsA, Psoriatic Arthritis; RA, Rheumatoid Arthritis; RADAI, Rapid Assessment of Disease Activity Index; REB, Research Ethics Board; SLE, Systemic Lupus Erythematosus.

\section{Funding}

Financial support was received from Janssen for the integration of the ACPAC ERP role.

\section{Disclosure}

The authors report no conflict of interests in this work.

\section{References}

1. Ozminkowski RJ, Burton WN, Goetzel RZ, Maclean R, Wang S. The impact of rheumatoid arthritis on medical expenditures, absenteeism, and short-term disability benefits. J Occup Environ Med. 2006;48 (2):135-148. doi:10.1097/01.jom.0000194161.12923.52

2. Breedveld F. The value of early intervention in RA-a window of opportunity. Clin Rheumatol. 2011;30(Suppl 1):S33-39. doi:10.1007/ s10067-010-1638-5

3. Bykerk V, Emery P. Delay in receiving rheumatology care leads to long-term harm. Arthritis Rheum. 2010;62(12):3519-3521. doi:10.1002/art.27691

4. Widdifield J, Bernatsky S, Bombardier C, Paterson M. Rheumatoid arthritis surveillance in Ontario: monitoring the Burden, quality of care and patient outcomes through linkage of administrative health data. Healthc Q. 2015;18(3):7-10. doi:10.12927/hcq.2015.24439

5. Widdifield J, Tu K, Carter Thorne J, et al. Patterns of care among patients referred to rheumatologists in Ontario, Canada. Arthritis Care Res (Hoboken). 2017;69(1):104-114. doi:10.1002/acr.22910

6. Tavares R, Pope JE, Tremblay JL, et al. Time to disease-modifying antirheumatic drug treatment in rheumatoid arthritis and its predictors: a national, multicenter, retrospective cohort. J Rheumatol. 2012;39 (11):2088-2097. doi:10.3899/jrheum.120100

7. Widdifield J, Paterson JM, Bernatsky S, et al. Access to rheumatologists among patients with newly diagnosed rheumatoid arthritis in a Canadian universal public healthcare system. BMJ Open. 2014;4 (1):e003888. doi:10.1136/bmjopen-2013-003888 
8. Arthritis Alliance of Canada. A Pan-Canadian Approach to Inflammatory Arthritis Models of Care. Toronto. 2014 April 30.

9. Arthritis Alliance of Canada. The Impact of Arthritis in Canada: Today and Over the Next 30 Years. Toronto Fall; 2011.

10. Barber CE, Jewett L, Badley EM, et al. Stand up and be counted: measuring and mapping the rheumatology workforce in Canada. J Rheumatol. 2017;44(2):248-257. doi:10.3899/jrheum.160621

11. Hunter TM, Boytsov NN, Zhang X, Schroeder K, Michaud K, Araujo AB. Prevalence of rheumatoid arthritis in the United States adult population in healthcare claims databases, 2004-2014. Rheumatol Int. 2017;37(9):1551-1557. doi:10.1007/s00296-0173726-1

12. American College of Rheumatology. Workforce Study of Rheumatology Specialists in the United States; 2015.

13. Widdifield J, Paterson JM, Bernatsky S, et al. The rising burden of rheumatoid arthritis surpasses rheumatology supply in Ontario. Can J Public Health. 2013;104(7):e450-455. doi:10.17269/cjph.104.4115

14. Widdifield J, Bernatsky S, Ahluwalia V, et al. Trends in encounters with rheumatologists in a publicly-funded single payer healthcare system. Ann Rheum Dis. 2018;77:834.

15. Widdifield J, Bernatsky S, Pope JE, et al. Encounters with rheumatologists in a publicly funded Canadian healthcare system: a population-based Study. $J$ Rheumatol. 2020;47(3):468-476. doi:10.3899/jrheum.190034

16. Widdifield J, Gatley JM, Pope JE. et al. Feminization of the rheumatology workforce: a longitudinal evaluation of patient volumes, practice sizes and physician remuneration. $J$ Rheumatol;2020. jrheum.201166. doi:10.3899/jrheum.201166

17. Lundon K, Shupak R, Schneider R, Herold McIlroy J. Development and early evaluation of an inter-professional post-licensure education programme for extended practice roles in arthritis care. Physiother Can. 2011;63(1):94-103. doi:10.3138/ptc.2009-35

18. Arthritis Community Research \& Evaluation Unit (ACREU). An Overview of Developments in Comprehensive Interdisciplinary Models of Care for Arthritis: Provider and Patient Perspectives. University Health Network; 2006 March.

19. Arthritis Community Research \& Evaluation Unit (ACREU). An Exploration of Comprehensive Interdisciplinary Models for Arthritis. Toronto: University Health Network;2005.

20. Ahluwalia V, Brooks S, Sweezie R, et al. The effect of triage assessments on identifying inflammatory arthritis and reducing rheumatology wait times in Ontario. $J$ Rheumatol. 2020;47(3):461-467. doi:10.3899/jrheum. 180734

21. Ahluwalia V, Larsen TH, Kennedy CA, Inrig T, Lundon K. An advanced clinician practitioner in arthritis care can improve access to rheumatology care in community-based practice. J Multidiscip Healthc. 2019;12:63-71. doi:10.2147/JMDH.S183397

22. Farrer C, Abraham L, Jerome D, Hochman J, Gakhal N. Triage of rheumatology referrals facilitates wait time benchmarks. J Rheumatol. 2016;43(11):2064-2067. doi:10.3899/jrheum.151235

23. ACPAC Program. Available from: www.acpacprogram.ca. Accessed April 17, 2020.

24. Smolen JS, Breedveld FC, Burmester GR, et al. Treating rheumatoid arthritis to target: 2014 update of the recommendations of an international task force. Ann Rheum Dis. 2016;75(1):3-15. doi:10.1136/ annrheumdis-2015-207524

25. Ferraz MB, Quaresma MR, Aquino LR, Atra E, Tugwell P, Goldsmith CH. Reliability of pain scales in the assessment of literate and illiterate patients with rheumatoid arthritis. J Rheumatol. 1990;17 (8):1022-1024.

26. Fransen J, Stucki G, van Riel PL. Rheumatoid arthritis measures: disease Activity Score (DAS), Disease Activity Score-28 (DAS28), Rapid Assessment of Disease Activity in Rheumatology (RADAR), and Rheumatoid Arthritis Disease Activity Index (RADAI). Arthritis Care Res. 2003;49(S5):S214-S224. doi:10.1002/art.11407
27. Fries JF, Spitz P, Kraines RG, Holman HR. Measurement of patient outcome in arthritis. Arthritis Rheum. 1980;23(2):137-145. doi:10.1002/art.1780230202

28. Bruce B, Fries JF. The Stanford health assessment questionnaire: a review of its history, issues, progress, and documentation. $J$ Rheumatol. 2003;30(1):167-178.

29. Smith JK, Falvo D, McKillip J, Pitz G. Measuring patient perceptions of the patient-doctor interaction. Development of the PDIS. Eval Health Prof. 1984;7(1):77-94. doi:10.1177/016327878400700106

30. Falvo DR, Smith JK. Assessing residents' behavioral science skills: patients' views of physician-patient interaction. $J$ Fam Pract. 1983;17(3):479-483.

31. Taenzer P, Bultz BD, Carlson LE, et al. Impact of computerized quality of life screening on physician behaviour and patient satisfaction in lung cancer outpatients. Psychooncology. 2000;9(3):203-213. doi:10.1002/1099-1611(200005/06)9:3<203::AID-PON453>3.0. $\mathrm{CO} ; 2-\mathrm{Y}$

32. Bowman MA, Herndon A, Sharp PC, Dignan MB. Assessment of the patient-doctor interaction scale for measuring patient satisfaction. Patient Educ Couns. 1992;19(1):75-80. doi:10.1016/0738-3991(92) 90103-P

33. Warmington K, Kennedy CA, Lundon K, et al. The patient perspective: arthritis care provided by advanced clinician practitioner in arthritis care program-trained clinicians. Open Access Rheumatol. 2015;7:45-53. doi:10.2147/OARRR.S85783

34. Davies AR, Ware JE. GHAA's Consumer Satisfaction Survey and User's Manual. 2 ed. Washington, DC: GHAA; 1991.

35. Ware JE Jr, Hays RD. Methods for measuring patient satisfaction with specific medical encounters. Med Care. 1988;26(4):393-402. doi:10.1097/00005650-198804000-00008

36. Kirwan JR, Mitchell K, Hewlett S, et al. Clinical and psychological outcome from a randomized controlled trial of patient-initiated direct-access hospital follow-up for rheumatoid arthritis extended to 4 years. Rheumatology (Oxford). 2003;42(3):422-426. doi:10.1093/ rheumatology $/$ keg 130

37. Primdahl J, Sorensen J, Horn HC, Petersen R, Horslev-Petersen K. Shared care or nursing consultations as an alternative to rheumatologist follow-up for rheumatoid arthritis outpatients with low disease activity-patient outcomes from a 2-year, randomised controlled trial. Ann Rheum Dis. 2014;73(2):357-364. doi:10.1136/annrheumdis2012-202695

38. Statistical Analytic System (SAS) [computer program]. Version 9.4. Gary, North Carolina, United States of America 2016.

39. Fullerton LM, Brooks S, Sweezie R, Ahluwalia V, Bombardier C, Gagliardi AR. Patient, Rheumatologist and therapist perspectives on the implementation of an Allied Health Rheumatology Triage (AHRT) initiative in Ontario Rheumatology Clinics. Pragmat Obs Res. 2020;11:1-12. doi:10.2147/POR.S213966

40. Aharony L, Strasser S. Patient satisfaction in primary health care: a literature review and analysis. Med Care Rev. 1993;50(1):49-79. doi:10.1177/002570879305000104

41. Carr-Hill RA. The measurement of patient satisfaction. J Public Health Med. 1992;14(3):236-249.

42. Pascoe GC. Patient satisfaction in primary health care: a literature review and analysis. Eval Program Plann. 1983;6(3-4):185-210. doi:10.1016/0149-7189(83)90002-2

43. Guldvog B. Can patient satisfaction improve health among patients with angina pectoris? Int J Qual Health Care. 1999;11(3):233-240. doi:10.1093/intqhe/11.3.233

44. Hurwitz EL, Morgenstern H, Yu F. Satisfaction as a predictor of clinical outcomes among chiropractic and medical patients enrolled in the UCLA low back pain study. Spine. 2005;30(19):2121-2128. doi:10.1097/01.brs.0000180639.67008.d0

45. Jackson JL. Communication about symptoms in primary care: impact on patient outcomes. J Altern Complement Med. 2005;11(Suppl 1): S51-S56. doi:10.1089/acm.2005.11.s-51 
46. Zhiwei Z, Gerstein DR, Friedmann PD. Patient satisfaction and sustained outcomes of drug abuse treatment. J Health Psychol. 2008;13(3):388-400. doi:10.1177/1359105307088142

47. Balsa A, Lojo-Oliveira L, Alperi-Lopez M, et al. Prevalence of comorbidities in rheumatoid arthritis and evaluation of their monitoring in clinical practice: the Spanish cohort of the COMORA study. Reumatol Clin. 2019;15(2):102-108. doi:10.1016/j. reuma.2017.06.002

48. Widdifield J, Ivers NM, Bernatsky S, et al. Primary care screening and comorbidity management in rheumatoid arthritis in Ontario, Canada. Arthritis Care Res (Hoboken). 2017;69(10):1495-1503. doi:10.1002/acr.23178
49. Dougados M, Soubrier M, Antunez A, et al. Prevalence of comorbidities in rheumatoid arthritis and evaluation of their monitoring: results of an international, cross-sectional study (COMORA). Ann Rheum Dis. 2014;73(1):62-68. doi:10.1136/annrheumdis-2013-204223

50. Wait Time Alliance. Wait time benchmarks for arthritis care; 2014. Available from: http://www.waittimealliance.ca/benchmarks/arthritiscare/. Accessed February 7, 2019.

51. Widdifield J, Bernatsky S, Thorne JC, et al. Wait times to rheumatology care for patients with rheumatic diseases: a data linkage study of primary care electronic medical records and administrative data. CMAJ Open. 2016;4(2):E205-212. doi:10.9778/cmajo.20150116

\section{Publish your work in this journal}

The Journal of Multidisciplinary Healthcare is an international, peerreviewed open-access journal that aims to represent and publish research in healthcare areas delivered by practitioners of different disciplines. This includes studies and reviews conducted by multidisciplinary teams as well as research which evaluates the results or conduct of such teams or healthcare processes in general. The journal covers a very wide range of areas and welcomes submissions from practitioners at all levels, from all over the world. The manuscript management system is completely online and includes a very quick and fair peer-review system. Visit http://www.dovepress.com/testimonials. php to read real quotes from published authors. 